\title{
IMPLEMENTASI KONSEPSI TUJUAN PEMBELAJARAN PAI UNTUK MENGHADAPI TUNTUTAN ERA REVOLUSI 4.0
}

\author{
Koko Adya Winata ${ }^{1}$, Sahudi ${ }^{2}$ Nurwadjah $^{3}$, Andewi Suhartini ${ }^{4}$ \\ 1. Universitas Sangga Buana Bandung, 2. UIN SGD Bandung 3. UIN SGD Bandung, 4. UIN SGD Bandung \\ adyawinata@gmail.com, sahudi8082@gmail.com,nurwadjah.ahmad@gmail.com, \\ andewi.suhartini@uinsgd.ac.id
}

\begin{abstract}
Abstrak
Tulisan ini mengkaji bagaimana implementasi konsepsi tujuan pembelajaran PAI untuk menghadapi era revolusi 4.0. Pendidikan merupakan sebuah keniscayaan yang harus tetap berlangsung ada karena menjadi sebuah kebutuhan setiap manusia. Pelaksanaan pendidikan harus senantiasa mengadaptasi dan merespon terhadap setiap perubahan dan perkembangan zaman. Implementasi Konsepsi tujuan pembelajaran PAI harus mampu melahirkan Sumber Daya Manusia yang adaptif dan kompetitif dalam menghadapi era revolusi 4.0. Metode yang digunakan dalam penelitian ini adalah metode kualitatif. Dengan menggunakan pendekatan kualitatif diharapkan peneliti dapat lebih leluasa dalam memahami, mengamati dan melakukan penelaahan lebih akurat berkenaan dengan implementasi pembelajaran PAI untuk menghadapi era revolusi 4.0. Implementasi pembelajaran PAI harus menfasilitasi pertumbuhan dalam semua aspeknya, baik aspek spiritual, intelektual, imajinasi, jasmaniah, ilmiah baik secara perorangan maupun kelompok yang lebih luas (ijtima'iyah) untuk menjadikan kholifatul ardhi yang unggul. Untuk menyiapkan SDM yang unggul rumusan pembelajaran PAI harus memperhatikan empat keterampilan yang dibutuhkan dan dikenal dengan skill 4Cs (Collaboratif skill, Creatif skill, Critical Thinking skill, dan Comunication skill).
\end{abstract}

Kata Kunci: Implementasi, Konsepsi Tujuan Pembelajaran PAI, Era Revolusi 4.0.

\begin{abstract}
This paper examines how the implementation of PAI's learning objectives conceptions to face the revolution era 4.0. Education is a necessity that must continue to exist because it is a necessity for every human being. The implementation of education must always adapt and respond to every change and development of the times. The implementation of the concept of PAI learning objectives must be able to give birth to adaptive and competitive Human Resources in the face of the 4.0 revolution era. The method used in this research is qualitative method. By using a qualitative approach researchers are expected to be more flexible in understanding, observing and conducting more accurate reviews regarding the implementation of PAI learning to face the revolution 4.0 era. The purpose of PAI learning is intended to foster the learners as a whole through psychiatric training, intelligence, reasoning, feelings and senses. The implementation of PAI learning must facilitate growth in all aspects, both spiritual, intellectual, imagination, physical, scientific aspects both individually and in broader groups (ijtima'iyah) to make Kholifatul Ardhi excel.
\end{abstract}

Keywords: Implementation, Conception of PAI Learning Objectives, Revolutionary Era 4.0. 


\section{Pendahuluan}

Rumusan pendidikan senantiasa tertuju kepada objek yang sama yaitu manusia. Tugas utama pendidikan yaitu meningkatkan sumber daya manusia yang mampu menghadapi tuntutan kehidupan yang terus berkembang sesuai dengan kebutuhan zamannya. Revolusi Industri 4.0 secara fundamental telah mengakibatkan berubahnya cara manusia berpikir, hidup, beraktivitas dan berhubungan satu dengan yang lain. Era ini telah mendistrupsi aktivitas manusia dalam berbagai bidang, tidak hanya dalam bidang teknologi saja, namun juga bidang yang lain seperti ekonomi, sosial, dan politik. Pada awalnya fenomena distrupsi berlaku hanya di bidang ekonomi. Namun Fenomena distrupsi telah meluas dalam bidang lainnya seperti pendidikan, pemerintahan, budaya, politik, dan hukum. Revolusi Industri 4.0 telah menerapkan konsep automatisasi yang dilakukan oleh mesin dan tidak lagi memerlukan keterlibatan tenaga manusia. Tuntutan era revolusi 4.0 ini telah menuntut konsepsi tujuan pendidikan yang harus mempersiapkan skill yang dapat melahirkan sumber daya manusia yang unggul. Keterampilan yang dibutuhkan untuk menghadapi tuntutan era revolusi 4.0 dikenal dengan skill 4Cs (Collaboratif skill, Creatif skill, Critical Thinking skill, dan Comunication skill) [1].

Islam sebagai syari'at yang sempurna telah mengatur seluruh aspek kehidupan termasuk dalam persoalan pendidikan. Alquran dan Hadist sebagai pedoman untuk seluruh tatanan kehidupan telah menjelaskan mengenai konsepsi tujuan pendidikan yang dapat melahirkan generasi - generasi yang unggul di zamannya. Islam sebagai ajaran agama yang dibawa oleh Nabi Muhammad SAW sebagai utusan yang terakhir berfungsi sebagai petunjuk bagi kehidupan umat manusia. Islam memiliki nilai ajaran universal yang sesuai dengan kebutuhan manusia dimana pun dan kapan pun. Karena Islam memiliki ajaran universal, maka ia memiliki kesempurnaan ajaran jika dibandingkan dengan ajaran sebelumnya. Kesempurnaan ajaran Islam dapat terlihat pada keselarasan fitrah manusia dengan nilainilai ajarannya, dalam arti selaras dengan kejadian alamiah manusia. Seluruh rumusan pendidikan selalu menempatkan pendidikan sebagai sarana yang strategis untuk melahirkan manusia yang terbina seluruh potensi dirinya (fisik, psikis, akal, spiritual, fitrah, talenta dan social) sehingga dapat melaksanakan pengabdiannya dalam rangka beribadah kepada Alloh SWT. [2]. Konsepsi tujuan pendidikan Islam tidak hanya mengembangkan potensi spiritual, namun terkait pula dengan upaya pengembangan potensi akal dan talenta serta kemampuan social yang dibutuhkan.

Tujuan pembelajaran PAI adalah idealitas dan cita-cita yang mengandung nilai-nilai yang hendak dicapai dalam proses pendidikan dengan berdasarkan kepada ajaran Islam. Tujuan pembelajaran PAI merupakan pengembangan nilai-nilai Islam yang hendak diwujudkan dalam pribadi peserta didik pada akhir setiap proses pendidikan. Peserta didik yang imannya kuat, jasmaninya sehat, akalnay cerdas dan cermat. Kreatif dan inovatif dalam bekerja cerdas dalam berfikr dan rajin dalam berdzikir adal tujuan dari pendidikan Islam. Oleh karena itu proses pendidikan Islam harus menyediakan jalan bagi pertumbuhan manusia dalam segala aspeknya; spiritual, intelektual, imajinasi, fisik, ilmiah, linguistic baik secara individual maupun secara kolektif, dan memotivasi semua aspek tersebut guna mencapai kebaikan dan kesempurnaan. Tujuan akhir pendidikan islam terletak pada realisasi penyerahan mutlak kepada Allah pada tingkat individual, masyarakat dan kemanusiaan pada umumnya [3]. Proses pendidikan Islam akan mampu mengarahkan dan mengantarkan umat manusia menjadi kreatif dan dinamis yang mampu menghadapi tantangan zaman serta mampu mencapai esensi nilai-nilai ubūdiyah.

Tujuan pembelajaran PAI mengandung di dalamnya suatu nilai-nilai tertentu sesuai dengan pandangan Islam sendiri yang harus direalisasikan melalui proses yang terarah dan konsisten dengan menggunakan berbagai sarana fisik dan non-fisik yang sama dengan nilai-nilainya. Tujuan pendidikan Islam merupakan penggambaran nilai nilai Islam yang hendak diwujudkan dalam pribadi peserta didik pada akhir dari proses kependidikan [4]. Pendidikan Islam bila dilihat dari sisi pentingnya, maka suatu 
pendidikan kedudukannya sangat urgen bagi kehidupan manusia karena terkait langsung dengan segala potensi yang dimiliki, merubah suatu peradaban, sosial masyarakat dan faktor manusia menuju kemajuan diperlukan suatu pendidikan, sebab pendidikan merupakan suatu sistem yang dapat memberikan kontribusi paradigma baru[5]. Seiring dengan era revolusi 4.0, bagaimana implementasi konsepsi tujuan pendidikan Islam dapat merespon tuntutan era tersebut agar menghasilkan peserta didik yang memiliki kompetensi yang unggul dalam rangka pengabdiannya kepada Alloh SWT sebagai kholifah di muka bumi. Manusia yang memiliki kompetensi dan keimanan yang kuat kepada kholiknya merupakan konsepsi tujuan pendidikan Islam. SDM yang aunggul dan handal dibarengi dengan sikap ubudiyah yang maksimal merupakan konsepsi dari tujuan pendidikan Islam.

\section{Metode Penelitian}

Metode penelitian yang dipergunakan dalam penelitian ini adalah metode kualitatif. Pendekatan penelitian kualitatif sering disebut sebagai metode penelitian naturalistik karena penelitiannya dilakukan pada kondisi yang alamiah (natural setting). Dalam penelitian kualitatif unsur kecermatan dan langkah yang sistematis memegang peranan sangat penting. Dengan menggunakan pendekatan kualitatif diharapkan peneliti dapat lebih leluasa dalam memahami, mengamati dan menganalisis serata melakukan penelaahan lebih akurat berkenaan dengan implementasi konsepsi tujuan pembelajaran PAI untuk menghadapi tuntutan era revolusi industri 4.0. Tuntutan akan sumber daya manusia yang handal berkenaan dengan era digitalisasi mengharuskan proses pembelajaran menekankan kepada pengembangan potensi peserta didik yang memiliki kompetensi yang dikenal dengan 4 Cs (Colaboratif skill, Creatif skill, Critical Thinking skill dan Comunication skill). Islam sebagai ajaran yang sempurna harus mampu melahirkan gernerasi yang unggul dalam menghadapi era revolusi 4.0. Oleh sebab itu, metode penelitian kualitatif dapat mendeskripsikan dan menjelaskan tentang konsepsi tujuan pendidikan Islam yang mampu menghadapi segala tantangan zaman sebagai wujud dari kholifatul ardhi yang memiliki kompetensi yang unggul.

\section{Hasil dan Pembahasan}

\section{Implementasi Konsepsi Tujuan Pembelajaran PAI}

Islam telah menawarkan konsepsi pendidikan yang sesuai dengan kondisi seluruh umat manusia, baik kondisi sosial, psikologis, akal, lingkungan, zaman dan maupun kondisi lainnya yang mampu memenuhi tujuan aktualisasi diri manusia. Pendidikan harus ditujukan ke arah pertumbuhan yang berkesinambungan dari kepribadian manusia yang menyeluruh melalui latihan spiritual, kecerdasan dan rasio, perasaan dan pancaindra. Oleh karenanya, maka pendidikan harus memberikan pelayanan kepada pertumbuhan manusia dalam semua aspeknya, yaitu aspek spiritual, intelektual, imajinasi, jasmaniah, ilmiah, linguistik, baik secara individual maupun secara kolektif, serta mendorong semua aspek itu ke arah kebaikan dan pencapaian kesempurnaan [6].

Tujuan pembelajaran PAI harus memiliki tiga kriteria, yaitu: pertama: tujuan harus dapat menciptakan perkembangan yang lebih baik daripada kondisi yang sudah ada; kedua: tujuan pendidikan harus fleksibel, yang dapat desesuaikan dengan keadaan; ketiga: tujuan itu harus mewakili kebebasan aktivitas. Pada akhirnya setiap tujuan harus mengandung nilai yang dirumuskan melalui observasi, pilihan dan perencanaan yang dilakukan dari waktu ke waktu [7]. Tujuan Pendidikan Sebagaimana yang tercermin dalam undang undang sistem pendidikan Nasional No 20 tahun 2003 BAB II pasal 3 yang berbunyi: Pendidikan Nasional berfungsi mengembangkan kemampuan dan membentuk watak serta peradaban bangsa yang bermanfaat dalam rangka mencerdaskan kehidupan bangsa, bertujuan untuk berkembangnya potensi peserta didik agar menjadi manusia yang beriman dan bertakwa kepada Tuhan 
Yang Maha Esa, berakhlak mulia, sehat, berilmu, cakap, kreatif, mandiri dan menjadi warga negara yang demokratis serta bertanggung jawab.

Adapun tujuan pendidikan Islam menurut Muhammad Fadhil al Jamaly, tujuan pendidikan Islam menurut al-Qurean meliputi; [8].

a. Menjelaskan posisi peserta didik sebagai manusia diantara makhluk Allah lainnya dan tanggung jawabnya dalam kehidupan ini. Tujuan pendidikan Islam memahamkan peserta didik agar menyadari kedudukannya sebagai makhluk ciptaan Alloh yang paling sempurna dibandingkan dengan makhluk yang lain. Perbedaan manusia dengan makhluk yang lain terletak pada dimensi pengetahuan, kesadaran dan keunggulan yang dimiliki manusia dibanding dengan makhluk lain. Sehingga penciptaan manusia sangat sempurna dilengkapi Allah dengan akal, perasaan dan kemauan atau kehendak. Dengan akal dan kehendaknya manusia akan tunduk dan patuh kepada Allah SWT.

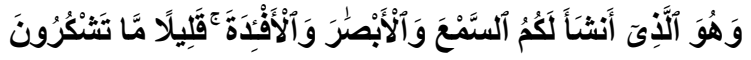

Artinya: "Dan Dialah yang telah menciptakan bagi kamu sekalian, pendengaran, penglihatan dan hati. Amat sedikitlah kamu bersyukur. (QS: Al Mukminun: 78).

b. Menjelaskan posisi peserta didik sebagai makhluk sosial dan tanggung jawabnya dalam tatanan kehidupan bermasyarakat. Tujuan pendidikan Islam memahamkan peserta didik agar dapat melangsungkan hubungan komunikasi dan interaksi di masyarakat.

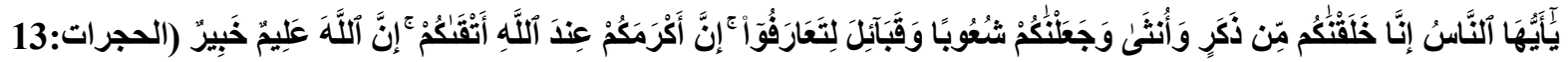

Artinya: Hai manusia, sesungguhnya Kami menciptakan kamu dari seorang laki-laki dan seorang perempuan dan menjadikan kamu berbangsa-bangsa dan bersuku-suku supaya kamu saling kenal-mengenal. Sesungguhnya orang yang paling mulia di antara kamu di sisi Allah ialah orang yang paling takwa di antara kamu. Sesungguhnya Allah Maha Mengetahui lagi Maha Mengenal. (QS: Al-hujurot: 13)

c. Menjelaskan hubungan manusia dengan alam dan tugasnya untuk mengetahui hikmah penciptaan dengan cara memakmurkan alam semesta. Salah satu sikap dan perilaku manusia terbadap alam dan isinya diwujudkan dalam bentuk pengetahuan tentang etika berkehidupan di alam ini, yaitu etika lingkungan. Pengetahuan tentang etika ini terus berkembang dan mengalami banyak perubahan dan kritik untuk memperbaiki hubungan manusia dengan alam beserta isinya. (Harry Mufrizon, 2005) Hubungan manusia dengan alam diajarakan agar manusia mampu mengelola alam semesta ini sesuai dengan kehendak penciptanya. Pengelolaan alam semesta secara professional agar tidak terjadi kerusakan lingkungan, dan dapat memaksimalkan alam raya ini untuk kelangsungan hidup manusia yang lebih bermaslahat. Hal tersebut dapat dilihat dari penegasan Alquran.

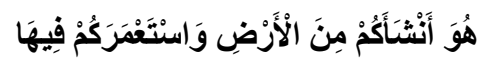

Artinya: "Dia telah menciptakan kamu dari bumi (tanah) dan menjadikan kamu pemakmurnya". (QS. Hud [11]: 61).

d. Menjelaskan hubungannya dengan Khaliq sebagai pencipta alam semesta. Manusia memang dicipta oleh Tuhan untuk mengabdikan hidupnya kepada Tuhan semesta alam. Manusia 
diciptakan hanya untuk berorentasi (mengarahkan pandangannya) kepada penciptanya. Sang pencipta yang menumbuhkan dan mengembangkan manusia, Dia memelihara, menjaga dan mendidik manusia. Dia pula yang memberi petunjuk hidup kepada manusia. Oleh karena itu, hanya kepada Dia manusia beribadah.

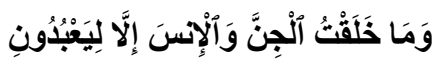

Artinya: “ Dan aku tidak menciptakan jin dan manusia melainkan supaya mereka mengabdi kepada-Ku. (QS: Adz Dzariyat: 51; 56)

Pendidikan Islam bertujuan untuk membentuk al-insan al-kamil atau manusia sempurna. Sehingga materi pendidikan yang ditawarkan Islam melingkupi: al-imaniyah (pendidikan iman), alkhuluqiyah (pendidikan akhlak), al-jismiyah (pendidikan jasmani), al aqliyah (pendidikan akal), al-nafsiyah (pendidikan jiwa), al-ijtimaiyah (pendidikan sosial), serta al-jinisiyah (pendidikan seks) [9]. Tujuan pendidikan Islam merupakan proses membimbing, mengembangkan dan membina fitrah peserta didik secara maksimal. Pendidikan Islam betujuan pada terciptanya pribadi peserta didik sebagai muslim paripurna (insan kamil) dalam menghambakan dirinya kepada Alloh SWT untuk meraih bahagia dunia dan akhirat.

\section{Tantangan Peserta Didik di Era Revolusi 4.0}

Era revolusi industri 4.0. dikenal juga dengan istilah era digitalisasi dan era distrupsi. Disebut era digitalisasi karena terjadinya proliferasi computer dan otomatisasi pencatatan serta dokumentasi di segala bidang. Era industri 4.0 juga disebut era distrupsi karena telah melahirkan teknologi robotic yang menggantikan tenaga manusia dalam berbagai sector pekerjaan. Secara umum, definisi revolusi industri adalah ketika kemajuan teknologi yang besar disertai dengan perubahan sosial ekonomi dan budaya yang signifikan. Terminologi Revolusi Industri 4.0 pertama kali dikenal di Jerman pada 2011. Pada Industri 4.0 ditandai dengan integrasi yang kuat terjadi antara dunia digital dengan produksi industri. Revolusi industri 4.0 merupakan era digital ketika semua mesin terhubung melalui sistem internet atau cyber system. Situasi ini membawa dampak perubahan besar di masyarakat [10]. Hakikat Industri 4.0, merupakan penggabungan teknologi fisik dan digital melalui analitik, kecerdasan buatan, teknologi kognitif, dan Internet of Things (IoT). Revolusi industri 4.0 telah menciptakan perusahaan digital yang saling terkait dan mampu menghasilkan keputusan yang lebih tepat.

Era Industri 4.0 menuntut terhadap ketersediaan profesional sumber daya manusia (SDM) yang memiliki kompetensi yang jauh berbeda dari sebelumnya. Era revolusi industri 4.0 juga telah mengubah cara pandang tentang pendidikan. Paradigma pendidikan mengalami perubahan yang sangat fundamental. Perubahan pendidikan dilakukan tidak hanya dalam cara mengajar, tetapi jauh yang lebih esensial, yakni perubahan cara pandang terhadap konsep pendidikan itu sendiri. Konsep revolusi industri 4.0 ini merupakan konsep yang pertamakali diperkenalkan oleh Profesor Klaus Schwab. Beliau merupakan ekonom terkenal asal Jerman sekaligus penggagas World Economic Forum(WEF) yang melalui bukunya, The Fourth Industrial Revolution, menyatakan bahwa revolusi industri 4.0 secara fundamental dapat mengubah cara kita hidup, bekerja, dan berhubungan satu dengan yang lain [11]. Menghadapi era revolusi 4.0, proses pembelajaran harus menciptakan SDM yang memiliki kompetensi yang dibutuhkan terkait dengan digitalisasi dan automatisasi. Pendidikan setidaknya harus mampu menyiapkan anak didiknya menghadapi tiga hal: [12].

a) Menyiapkan anak untuk bisa bekerja yang pekerjaannya saat ini belum ada.

b) Menyiapkan anak untuk bisa menyelesaikan masalah yang masalahnya saat ini belum muncul. 
c) Menyiapkan anak untuk bisa menggunakan teknologi yang sekarang teknologinya belum ditemukan. Sungguh sebuah pekerjaan rumah yang tidak mudah bagi dunia pendidikan. Untuk bisa menghadapi tantangan tersebut, syarat penting yang harus dipenuhi adalah bagaimana menyiapkan kualifikasi dan kompetensi guru yang berkualitas.

Pada era revolusi industri 4.0, pembelajaran harus lebih banyak memberikan kesempatan pada siswa untuk kreatif, memecahkan masalah, mengoptimalkan kemampuan literasi dan numeracy, kolaborasi, dan berpikir kritis. kemampuan pendidik dan peserta didik dalam menggunakan ICT merupakan salah satu solusi untuk menyiapkkan generasi milineal yang kompeten. Lembaga pendidikan harus dapat mempersiapkan sumber daya manusia yang responsive, adaptif dan handal untuk menghadapi revolusi industri. Peserta didik harus memiliki kemampuan dalam hal data Information Technology (IT), Operational Technology (OT), Internet of Things (IoT), dan Big Data Analitic. mengintegrasikan objek fisik, digital dan manusia untuk menghasilkan lulusan perguruan tinggi yang kompetitif dan terampil terutama dalam aspek data literacy, technological literacy and human literacy [13].

\section{Implementasi Tjuan Pembelajaran PAI di Era Revolusi 4.0.}

Pendidikan merupakan proses transformasi dan internalisasi ilmu pengetahuan dan nilai-nilai Islam pada peserta didik melalui penumbuhan dan pengembangan potensi fitrahnya untuk mencapai keseimbangan dan kesempurnaan hidup dalam segala aspeknya [14]. Tujuan pendidikan Islam mempunyai corak yang berbeda dengan pendidikan umum. Pendidikan umum hanya bertujuan mentransfer ilmu pengetahuan dan mengantarkan kedewasaan berfikir peserta didik. Esensinya hanya bersifat profan. Berbeda dengan pendidikan Islam yang mempunyai tujuan lebih holistic membentuk peserta didik yang sukses dunia dan akhirat [15]. Pendidikan Islam berpandangan bahwa hubungan antara manusia -Tuhan dan alam semesta tidak bisa dipisahkan Tujuan pembelajaran PAI dapat dilihat dari tujuh dimensi utama, yaitu dimensi hakikat penciptaan manusia, dimensi tauhid, dimensi moral, dimensi perbedaan individu, dimensi sosial, dimensi profesional, dan dimensi ruang dan waktu. Dimensi-dimensi tersebut sejalan dengan tataran pendidikan dalam al-Quran yang prosesnya terentang dalam lintasan ruang dan waktu yang cukup panjang.

Orientasi dan tujuan yang ingin dicapai oleh pendidikan dalam Islam harus merangkum semua tujuan yang terkait dalam rentang ruang dan waktu tersebut. Dimensi kehidupan ideal Islam mengandung nilai yang dapat meningkatkan kesejahteraan hidup manusia di dunia untuk mengelola dan memanfaatkan dunia sebagai bekal kehidupan di akhirat, serta mengandung nilai yang mendorong manusia berusaha keras untuk meraih kehidupan di akhirat yang lebih membahagiakan, sehingga manusia dituntut untuk tidak terbelenggu dengan kesenangan dan kemewahan dunia semata [16]. Untuk menciptakan sumber daya manusia SDM yang unggul di era revolusi industri 4.0 maka proses pendidikan Islam harus mengajarkan kompetensi yang handal dan dikenal dengan istilah 4Cs (Comunication skill, Collaboratif skill, Creatif skill, Critical Thinking skill, dan). Islam sebagai agama yang sempurna sudah barang tentu sudah memiliki ajaran untuk menciptakan manusia yang memiliki kompetensi tersebut.

\section{a. Kemampuan Komunikasi ( Comunication skill).}

Komunikasi adalah proses pemindahan informasi dari seseorang kepada orang lain. Karena itu komunikasi merupakan cara mencapai orang lain dengan memindahkan gagasan, fakta, pikiran, perasaan dan nilai. Komunikasi sangat strategis dalam membuat seseorang memahami informasi atau pesan yang dikirimkan kepada orang lain. Komunikasi berarti manifestasi eksistensi manusia di hadapan orang lain dalam semua aspek kehidupan manusia 
[17]. Dalam ajaran Islam, kemampuan berkomunikasi harus dimiliki oleh kaum muslimin sebagaimana halnya Alquran menjelaskan bahwa para nabi menyampaikan risalah Alloh SWT memiliki kemampuan berkomunikasi yang baik.

$$
\text { وما أرسلنا من رسول إلا بلسان قومه ليبين لهم فيضل الله من يثاء ويهدي من يثاء وهو العزيز الحكيم }
$$

Artinya: "Kami tidak mengutus rasulpun, berbicara dengan bahasa kaumnya, meminta ia memberikan penjelasan dengan terang kepada mereka. Maka Allah menyesatkan siapa yang Dia kehendaki, dan memberi petunjuk kepada siapa yang Dia kehendaki. Dan Dialah Tuhan Yang Maha Kuasa lagi Maha Bijaksana. (QS: Ibrahim, 14:4)

Ajaran Islam mengajarkan pentingnya komunikasi sebagaimana halnya telah menjadi tuntutan proses pendidikan di era revolusi 4.0. Al-Qur'an memberikan kata kunci (key concept) yang berhubungan dengan hal itu. Komunikasi diartikan dengan kata kunci al-bayan sebagai kemampuan berkomunikasi. Selain itu, kata kunci yang diperguna-kan Al Qur'an untuk komunikasi ialah al-qaul. Setidaknya ada enam prinsip komunikasi dalam Al-Qur'an: a) Qaulan sadidan (perkataan, benar, lurus, jujur). b) Qaulan baliigan (perkataan yang membekas pada jiwa), c) Qaulan kariman (perkataan yang mulia) d) Qaulan Layyinna (perkataan yang lemah lembut), e) Qaulan Maesyuran (perkataan yang ringan), f) Qaulan ma'ruufan (perkataan yang baik) [18]. Bentuk komunikasi yang diajarkan Nabi Muhamad SAW kepada kita sebagai ummatnya melalui.

\section{1) Komunikasi Verbal.}

Komunikasi verbal adalah komunikasi yang menggunakan kata-kata, entah lisan maupun tulisan atau bentuk komunikasi yang menggunakan kata-kata, baik dalam bentuk percakapan maupun tulisan (speak language). Untuk mengungkapkan perasaan, emosi, pemikiran, gagasan, atau, fakta, data, dan informasi [19]. Dalam ajaran Islam setiap muslim ketika bertemu harus mengucapkan salam baik kepada yang kau kenal maupun tidak kau kenal. Ini ajaran yang mengharuskan agar manusia memiliki keterampilan berkomunikasi.

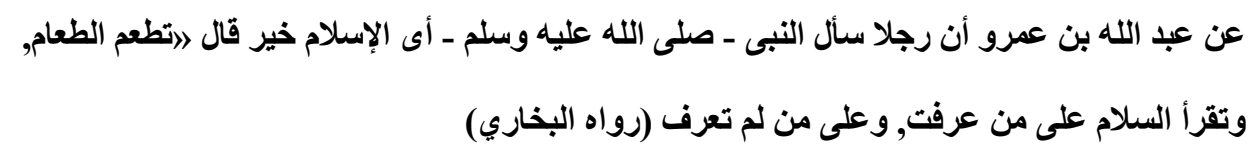

Artinya: "Dari 'Abdullah bin' Amr, ada yang bertanya pada Nabi shallallahu 'alaihi wa sallam tentang islam bagaimana yang baik. Dia menjawab, "memberikan makan (pada orang yang membutuhkan), serta meminta salam pada orang yang dikenal dan tidak dikenal." (HR. Bukhari no. 6236).

\section{2) Komunikasi Non Verbal.}

Komunikasi Non verbal adalah bentuk komunikasi yang menggunakan bahasa isyarat tau bahasa diam (silent language). untuk menyampaikan pesannya. Melalui komunikasi nonverbal kita bisa mengetahui suasana emosional seseorang, apakah ia sedang bahagia, marah, bingung, atau sedih. Komunikasi non verbal mencakup semua rangsangan (kecuali rangsangan verbal) dalam suatu setting 
komunikasi, yang dihasilkan oleh individu [20]. Dalam berkomunikasi terlebih dahulu harus memahami lawan yang akan diajak berkomunikasi. Mengenal seseorang sering didasarkan pada perilaku non verbalnya. Komunikasi non verbal yang dicontohkan nabi dengan senantiasa tersenyum. Komunikasi dengan tersenyum telah menjadi salah satu variable dalam berdakwah yang telah menjadikan ajaran Islam diterima dimasyarakat jahiliyah.

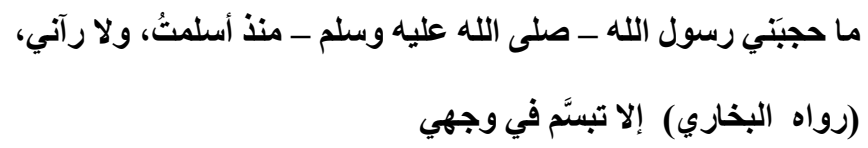

Artinya:" "Sejak aku masuk Islam, Rasulullah Shallallahu'alaihi Wasallam tidak pernah menghindari aku jika aku ingin bertemu dengannya, dan tidak pernah aku melihat beliau kecuali beliau tersenyum padaku" (HR. Bukhari, no.6089).

\section{b. Kemampuan Kolaborasi (Collaboratif Skill)}

Keterampilan kolaborasi adalah suatu kemampuan dalam bekerja sama megerjakan sesuatu secara bersama - sama dengan satu tujuan. Kolaborasi menekankan pentingnya pengembangan belajar secara bermakna dan pemecahan masalah secara intelektual serta pengembangan aspek sosial. Keterampilan kolaborasi adalah sebuah proses dalam belajar yang dilakuakn secara bersama-sama untuk mengimbangi perbedaan pandangan, pengetahuan, berperan dalam diskusi dengan memberikan saran, mendengarkan, mendukung satu sama lain [21]. Dalam ajaran Islam, kemampuan kolaborasi harus menjadi keterampilan yang dimiliki oleh manusia terutama kaum muslimin untuk mengembangkan kelangsungan hidupnya. Kemampuan kolaborasi bagian dari kompetensi yang harus dipersiapkan di era revolusi industri 4.0 dan juga amanat ajaran Islam.

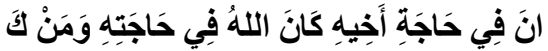

Artinya: "Barang siapa memenuhi kebutuhan saudaranya, niscaya Allah subhanahu wa ta'ala akan memenuhi kebutuhannya." ( HR.al-Bukhari Kitabul Mazhalim wal Ghashab no. 2442, Muslim Kitabul Birri wash Shilah no. 2580, atTirmidzi Kitabul Hudud no. 1426, dan Abu Dawud Kitabul Adab no. 4893)

\section{c. Kemampuan Berpikir Kritis (Critical Thinking skill).}

Berpikir kritis sebagai cara berpikir rasional dan reflektf dalam membuat keputusan tentang hal yang harus dipercayai atau dilakukan. Rasional berarti mempunyai keyakinan dan pandangan yang disertai oleh bukti yang standar, aktual, cukup dan relevan; reflekif berarti harus mempertimbangkan secara ktif, hati-hati dan tekun segala alternatif solusi pemecahan masalah sebelum mengambil keputusan. Berpikir kritis merupakan bagian dari cognitive skill yang meliputi interpretasi (interpretation), analisis (analysis), evaluasi (evaluation), inferensi (inference), penjelasan (explanation), serta pengaturan diri (self regulation) [22]. Kosep berpikir kritis diajarkan dalam Islam sebagaimana halnya Nabi SAW menyuruh sahabatnya untuk bertanya dan menganalisa suatu maslah dengan sksama menggunakan potensi yang dimiliki. Konsep berfikir kritis dalam Islam dikenal 
dengan istilah Ijtihad. Mencurahkan semua kemampuan untuk mencari (jawaban) hukum yang bersifat dzanni, hingga merasa dirinya tidak mampu untuk mencari tambahan kemampuannya itu disebut ijtihad.

Menurut Al-Ghazali merumuskan ijtihad sebagai berikut : Pencurahan kemampuan seorang mujtahid dalam rangka memperoleh hukum-hukum syar'I

Ijtihad dilakukan untuk menjawab permasalahan yang timbul di masyarakat yang belum diketahui status hukumnya [23]. Dasar Hukum yang lain terdapat dalam Hadis Nabi ketika Nabi mengutus Muaz Bin jabbal menjadi hakim di Yaman dengan pertanyaan Nabi yang artinya "Bagiamana Muaz menetapkan hukum apabila dihadapkan kepada muaz suatu masalah, maka muaz menjawab dengan AlQuran, lalu Rasul kembali bertanya Jika tidak ditemukan, maka muaz menjawab dengan Sunnah Rasullullah, kemudian Nabi bertanya lagi jika juga tidak ditemukan, maka muaz menjawab muaz akan berijtihad dengan pemikirannya...”. (HR Abu daud dan at-Tirmizi) [24].

\section{d. Kemampuan Kreatif (Creatif skill).}

Berpikir kreatif merupakan sebuah proses yang melibatkan unsur-unsur orisinalitas, kelancaran, fleksibelitas, dan elaborasi. Hal tersebut menunjukan bahwa berfikir kreatif dapat mengembangkan daya pikir yang mencakup wawasan dengan unsur unsur yang luas [25]. Indikator dari kemampuan kreatif adalah kelancaran (fluency), fleksibilitas (flexibility) dan kebaruan (novelty). Islam mengajarkan kepada ummat manusia untuk senantiasa berfikir dan melihat peristiwa yang sudah terjadi di jaman ummat dahulu untuk dijadikan pelajaran dan bahan kajian.Ini lah ajaran yang mengharuskan kaum muslimin untuk memiliki kompetensi Creatif Skill. Alquran menyatakan sebagai berikut:

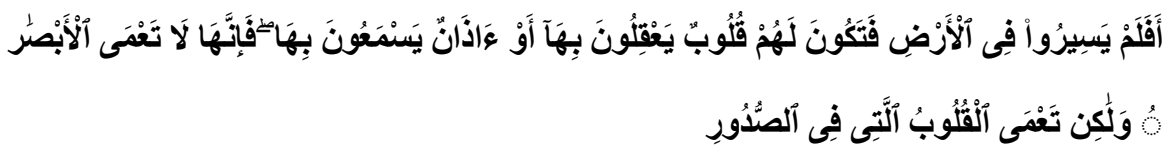

Artinya: maka apakah mereka tidak berjalan di muka bumi, lalu mereka mempunyai hati yang dengan itu mereka dapat memahami atau mempunyai telinga yang dengan itu mereka dapat mendengar? Karena sesungguhnya bukanlah mata itu yang buta, tetapi yang buta, ialah hati yang di dalam dada. (QS: Al Haj, 22: 46)

\section{Kesimpulan}

Pendidikan Agama Islam bertujuan untuk membentuk al-insan al-kamil atau manusia sempurna. Sehingga materi pendidikan yang ditawarkan Islam melingkupi: al-imaniyah (pendidikan iman), alkhuluqiyah (pendidikan akhlak), al-jismiyah (pendidikan jasmani), al aqliyah (pendidikan akal), al-nafsiyah (pendidikan jiwa), al-ijtimaiyah (pendidikan sosial), serta al-jinisiyah (pendidikan seks). Era revolusi industri 4.0 telah mengubah cara pandang tentang pendidikan. Paradigma pendidikan mengalami perubahan yang sangat fundamental. Perubahan pendidikan dilakukan tidak hanya dalam cara mengajar, tetapi jauh yang lebih esensial, yakni perubahan cara pandang terhadap konsep pendidikan itu sendiri. Untuk menciptakan sumber daya manusia SDM yang unggul di era revolusi industri 4.0 maka proses pendidikan Islam harus mengajarkan kompetensi yang handal dan dikenal dengan istilah 4Cs (Comunication skill, Collaboratif skill, Creatif skill, Critical Thinking skill, dan). Islam sebagai agama yang sempurna sudah barang tentu sudah memiliki ajaran untuk menciptakan manusia yang memiliki kompetensi tersebut. 


\section{DAFTAR PUSTAKA}

[1]. Qiqi Yuliati Zakiah, Kapita Selekta Ilmu Pendidikan, Bandung: Mimbar Pustaka, 2019: 3.

[2]. Abuddin Nata,,Ilmu Pendidikan Islam, Jakarta: Prenadamedia Goup, 2016: 31.

[3]. Ahmad Tafsir, Ilmu Pendidikan Islami, Bandung: Remaja Rosdakarya, 2017: 67.

[4]. Muhammad Rusmin B., Konsep dan Tujuan Pendidikan Islam, Jurnal UIN Alaudin Makasar, 2017: Volume VI, Nomor 1: 73.

[5]. S. Hidayat \& Wakhidah,. Konsep Pendidikan Islam Ibnu Khaldun Relevansinya Terhadap Pendidikan Nasional. Profetika, Jurnal Studi Islam, 2015: Volume 16 (1): 93

[6]. Abuddin Nata, „Ilmu Pendidikan Islam, Jakarta: Prenadamedia Goup, 2016: 30.

[7]. Tejo Waskito, KONSEP TUJUAN PENDIDIKAN IS1LAM, Disampaikan dalam Diskusi Rutin Dosen Komunitas Mahasiswa Lampung, 25 September 2018 : 54.

[8]. Abdul Mujib, Jusuf Mudzakir, Ilmu Pendidikan Islam, Jakarta: Kencana, 21014: 83.

[9]. Safrudin Aziz, Pemikiran Pendidikan Islam, Yogyakarta: KALIMEDIA, 2015: 169.

[10]. Syamsuar, Reflianto, PENDIDIKAN DAN TANTANGAN PEMBELAJARAN BERBASIS TEKNOLOGI INFORMASI DI ERA REVOLUSI INDUSTRI 4.0 , Jurnal E-Tech, 2018: Vol.6, No. 2: 47.

[11]. Delipiter Lase, Pendidikan di Era Revolusi Industri 4.0, JURNAL SUNDERMANN, 2019: vol. 1, No., 1: 30.

[12]. Sukartono, Revolusi Industri 4.0 dan Dampaknya terhadap Pendidikan di Indonesia, Makalah FIP PGSD Universitas Muhammadiyah Surakarta. 2018: 30.

[13]. MUHAMMAD YAHYA, ERA INDUSTRI 4.0: TANTANGAN DAN PELUANG PERKEMBANGAN PENDIDIKAN KEJURUAN INDONESIA, Makasar: UIN Makasar, $2018: 14$.

[14]. Sada, h. J., Pendidik Dalam Perspektif al-Qur'an. Al-Tadzkiyyah: Jurnal Pendidika Islam: 2015: vol. 6, no. $2: 103$.

[15]. Imam Syafee', TUJUAN PENDIDIKAN ISLAM, Al-Tadzkiyyah: Jurnal Pendidikan Islam, 2015: Volume 6, November 2015 P. ISSN: 20869118, 19.

[16]. As'aril Muhajir, TUJUAN PENDIDIKAN DALAM PERSPEKTIF AL-QUR'AN , Al-Tahrir, 2011 : Vol.11, No. 2, 246.

[17]. Ahmad Taufik Al Afkari S., KETERAMPILAN KOMUNIKASI GURU PROFESIONAL DI SEKOLAH, IJTIMAIYAH , 2018: Vol.2 No.1, 38. ISSN 2541-660X.

[18]. Muslimah, ETIKA KOMUNIKASI DALAM PERSFEKTIF ISLAM, Jurnal Sosial Budaya, 2016: Vol. 13, No. 2: 68. (e-ISSN 2407-1684 | p-ISSN 1979-2603.

[19]. TRI INDAH KUSUMAWATI, KOMUNIKASI VERBAL DAN NONVERBAL, Jurnal AlIrsyad: Pendidikan dan Konseling, 2016: Vol. 6 No. 2: 76.

[20]. Rina Nurmala, KOMUNIKASI VERBAL DAN NONVERBAL DALAM PROSES KEGIATAN BELAJAR MENGAJAR, (Studi Kasus pada Kegiatan Belajar Mengajar di Rumah Bintang Gang Nangkasuni, Wastukencana Bandung), e-Proceeding of Management, 2016: Vol.3, No.1:802.

[21]. Halani Felda Sunbanu, Mawardi, Krisma Widi Wardani, PENINGKATAN KETERAMPILAN KOLABORASI SISWA MENGGUNAKAN MODEL PEMBELAJARAN KOOPERATIF TWO STAY TWOSTRAY DI SEKOLAH DASAR, Jurnal Basicedu, 2019: Volume 3Nomor 4: 2041.

[22]. Susilowati, Sajidan, Murni Ram, Analisis Keterampilan Berpikir Kritis Siswa Madrasah Aliyah Negeri di Kabupaten Magetan, "Strategi Pengembangan Pembelajaran dan Penelitian Sains untuk Mengasah Keterampilan Abad 21 (Creativity and Innovation, Critical Thinking and Problem Solving, Communication, Collaboration/4C) Prosiding Seminar Nasional Pendidikan Sains (SNPS), 2017: 223.

[23]. Abd. Salam Arief, Ijtihad dan Dinamika Hukum Islam, Jurnal Agama dan Hak Azazi Manusia, 2017: Vol. 7, No. 1: 17. 
[24]. Zahratul Idami, IJTIHAD DAN PENGARUHNYA TERHADAP PERKEMBANGAN

KETATANEGARAAN DALAM SEJARAH ISLAM, Kanun Jurnal Ilmu Hukum Ijtihad dan Pengaruhnya terhadap Perkembangan Ketatanegaraan dalam Sejarah Islam, 2011: Vol. XIII No. 55: 89.

[25]. Yeyen Febrianti, Yulia Djahir, Siti Fatimah, ANALISIS KEMAMPUAN BERPIKIR KREATIF PESERTA DIDIK DENGAN MEMANFAATKAN LINGKUNGAN PADA MATA PELAJARAN EKONOMI DI SMA NEGERI 6 PALEMBANG, JURNAL PROFIT, 2016: VOLUME 3, NOMOR 1: 35. 